\title{
Selective-Harmonic Elimination with An Optimized Multicarrier Modulation Techniques for Cascaded H-Bridge Multilevel Inverter
}

\author{
Babkrani Youssef, Naddami Ahmed, Hayani Sanaa, and Hilal Mohamed \\ Department of Electrical Engineering University of Hassan $1^{\mathrm{ST}}$ Faculty of Science and Technical, Settat, Morocco
}

\begin{abstract}
How to cite this paper: Babkrani Y, Naddami A, Hayani S, Hilal M (2019) Selective-harmonic elimination with an optimized Multicarrier Modulation Techniques for Cascaded H-Bridge Multilevel Inverter. Journal of Applied Mathematics and Computation, 3(1), 574-582. DOI: 10.26855/jamc.2019.01.001

*Corresponding author: Babkrani Youssef, Department of Electrical Engineering University of Hassan 1ST Faculty of Science and Technical, Settat, Morocco.

Email: y.babkrani@gmail.com
\end{abstract}

\begin{abstract}
Power Quality has been a problem ever since electrical power was invented and in recent years, it has become the main interest of researchers who are still concerned about finding ways to reduce its negative influence on electrical devices. Harmonics are an important factor in power quality and also to maintain stable power supply performance, so inverters with harmonic reduction is required. In this paper, several multicarrier techniques are evaluated for cascaded $\mathrm{H}$ bridge multilevel inverter and being implemented with several level-shifted Pulse Width Modulation (PWM) techniques such as phase disposition (PD), phase opposition disposition (POD) and alternative phase opposition disposition (APOD). The line voltage and total Harmonics Distortion (THD) are acquired and are compared with the conventional technique.

We also propose a modification on trapezoidal multicarrier aiming to reduce the harmonics. This modification introduces a sinusoidal wave compared with modified trapezoidal multi-carrier to generate the pulses.

To know which technique is the best, these PWM techniques are simulated via MATLAB/SIMULINK. R2014a in order to obtain the line voltages and the total harmonic distortions (THD) .
\end{abstract}

\section{Keywords}

Triangular carrier waveform, trapezoid carrier waveform, phase disposition (PD), phase opposition disposition (POD), alternative phase opposition disposition (APOD), total Harmonics Distortion (THD)

\section{Introduction}

Nowadays the world community relies heavily on non-renewable energies, but just after the big oil crisis the use of renewable energy has greatly increased and has become the main interest of many countries for its many advantages such as: minimal impact on the environment, renewable generators requiring less maintenance than traditional ones and it has also a great financial impact on economy [1].

It is easy to get charmed by the advantages of using the renewable resources but we must also be aware of their disadvantages.

One of the major disadvantages is that the renewable energy resources are intermittent and thus they have led scientists to develop new semiconductor power converters among which is the multilevel converter used in medium voltage and high voltage [2].

These inverters convert the available direct current supplied by the PV panels or batteries and produce a staircase output waveform used to feed the grid.

One of the major advantages of multilevel inverters is the remarkable improvement of the spectral quality of the output signals and therefore they have proven to be more effective than the conventional two-level inverters.

In addition, two-level inverters are exposed to thermal stresses created by converting the full voltage imposed by the continuous source, so the performance and lifetime of its components are actually affected whereas using the limitation of 
voltage, multilevel inverters reduce such stresses by splitting continues tension introduced to the inverter .

To reduce this kind of problem researchers are in the hunt of new kind of architectures and switching techniques.

In this scenario, a new switching technique is evolved and it's quite promising when compared with traditional techniques.

There are two pulses with modulation techniques used to control multilevel inverters: the first depends on fundamental switching frequency and the other depends on high switching frequency [3].

Thus my focus will be on this latter especially sinusoidal pulse width modulation (SPWM) because it is simple, easy to implement and widely used.

In this paper, multiple multi-carrier SPWM methods for cascaded h-bridge are simulated, analyzed and compared with the conventional SPWM technique. Those carriers are being implemented with different sinusoidal dispositions PDPWM, PODPWM and APODPWM and with two different frequencies (1 KHz and $2 \mathrm{KHz}$ ).

\section{Cascaded H Bridge Multilevel inverters}

The first model of inverters was the H-bridge which appeared in 1975, the cascaded multilevel inverter (CMLI) was created from it by connecting those H-bridges in series and was used for the first time in plasma application in 1988.

The output of the CMLI is the sum of the outputs of H-bridge inverters connected in series [4] so the more $\mathrm{H}$ inverters are used the more levels of the output waveform are created and the shape becomes approximate to sinusoidal waveform.

This topology is suitable more for applications where separate DC voltage sources are used, such as batteries, fuel cells and photovoltaic generators [5].

Figure 1 shows the output voltage of the chosen topology. The Cascaded H-bridge inverter was fed by seven separate PV panels each giving $21 \mathrm{~V}$ as DC sources and produces fifteen levels output.

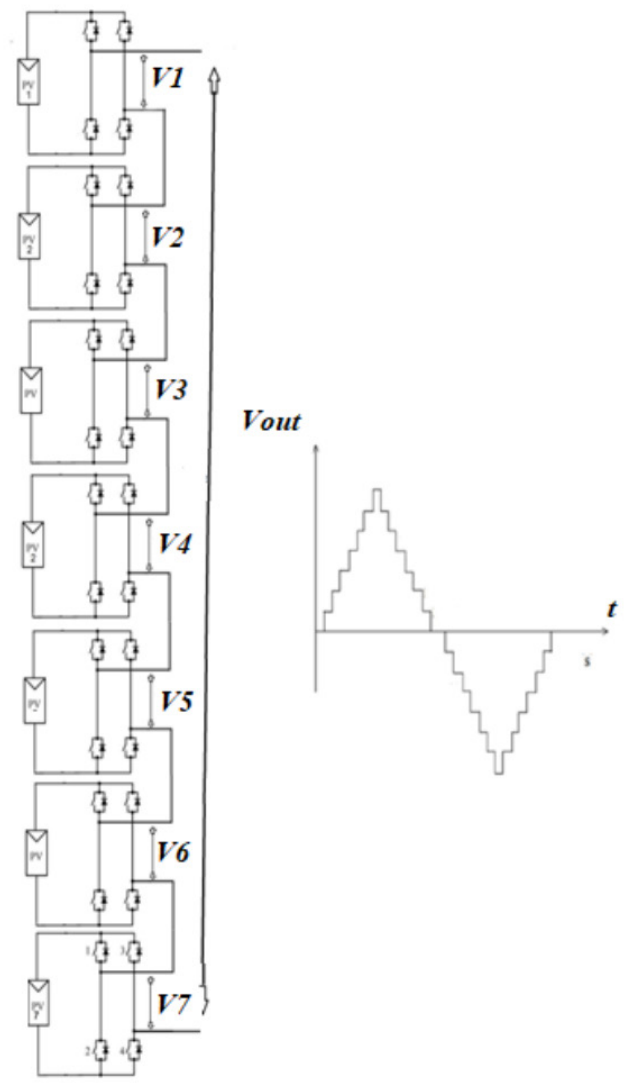

Figure 1 Solar PV panels feeding fifteen levels inverter with the output waveform

The output voltage can be expressed as:

$$
\mathrm{V}_{\text {out }}=\mathrm{V}_{1}+\mathrm{V}_{2}+\mathrm{V}_{3}+\mathrm{V}_{4}+\mathrm{V}_{5}+\mathrm{V}_{6}+\mathrm{V}_{7}
$$

This is because all the full bridge inverters are connected in series. Each full bridge inverter can generate three levels $-V_{d c}$, 0 and $+\mathrm{V}_{\mathrm{dc}}$. 


\section{Sinusoidal PWM Analysis}

Sinusoidal Pulse Width Modulation is the simplest technique that can be used to control multilevel inverters. Basically, in Sinusoidal Pulse Width Modulation, a sinusoidal signal with low frequency is continuously compared with high frequency to generate the control signals [6]. If the sinusoidal signal is greater than the carrier signal, then devices corresponding to that carrier become active, and if the sinusoidal signal is lesser than the carrier signal, then the devices corresponding to that carrier become inactive.

Figure 2 shows the Sinusoidal Pulse Width Modulation setup in Matlab platform for a fifteen level inverter.

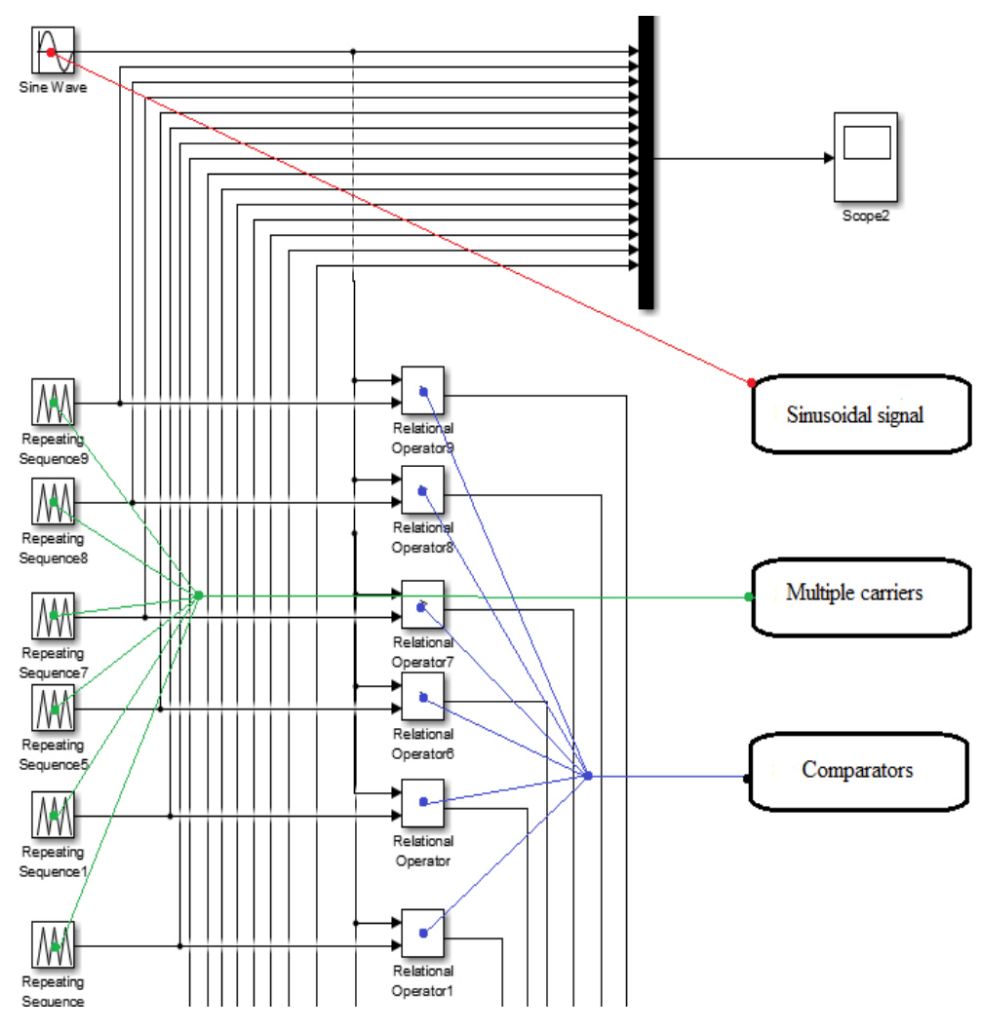

Figure 2 Sinusoidal Pulse Width Modulation in Matlab platform

\section{PWM Dispositions}

There are different categories of sinusoidal pulse width Modulation technique such as Phase disposition, Phase opposite disposition and Alternative phase opposite disposition [7].

\section{1 Phase disposition (PD)}

Phase disposition PWM is the most used method because it gives the lowest harmonic distortion compared to the other two. In the Phase disposition PWM carriers are in the same phase Figure 3.

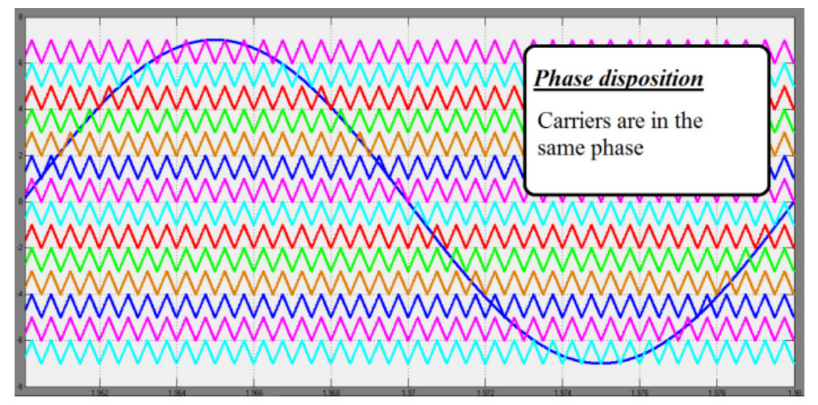

Figure 3 Carriers arrangement for phase disposition PWM 


\subsection{Phase opposite disposition: (POD)}

The difference between POD and PD techniques is that carriers above zero are $180^{\circ}$ phase shifted with those below the zero [8], Figure 4.

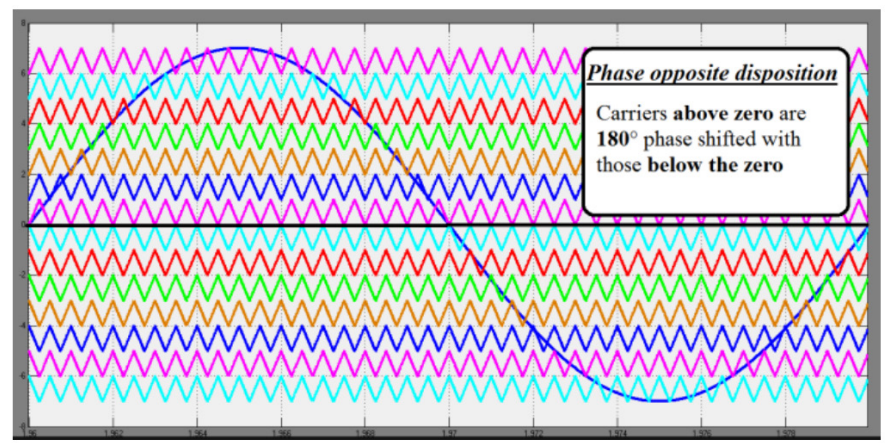

Figure 4 Carriers arrangement for phase opposite disposition PWM

\subsection{Alternative phase opposite disposition (APOD)}

This method of modulation is quite different from the two above in which the carriers are alternately phase shifted Figure 5.

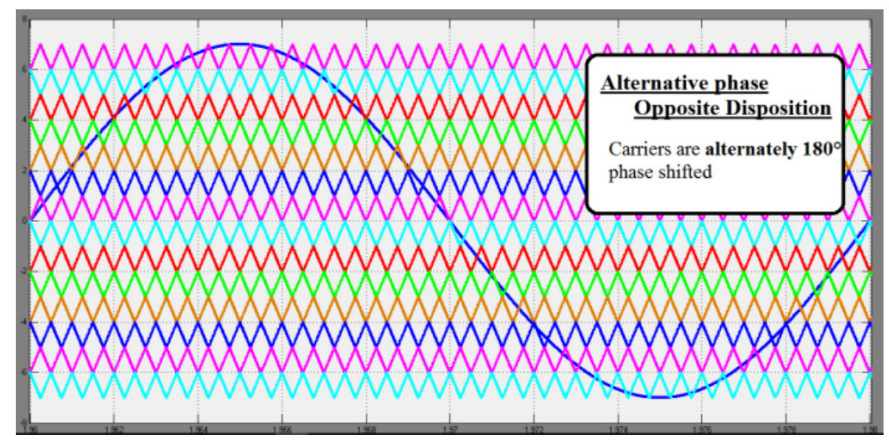

Figure 5 Carrier arrangement for Alternative phase opposite disposition PWM

\section{Simulation Multiple Carriers of Fifteen-level Inverter}

As discussed in previous works [9], the multi-carrier modulation technique can increase the performances of the multilevel inverters.

According to this system, different multi-carrier modulation techniques are used and the performances are analyzed to prove the best. Figure 6 shows the test setup to analyze the performances of cascaded fifteen levels inverter.

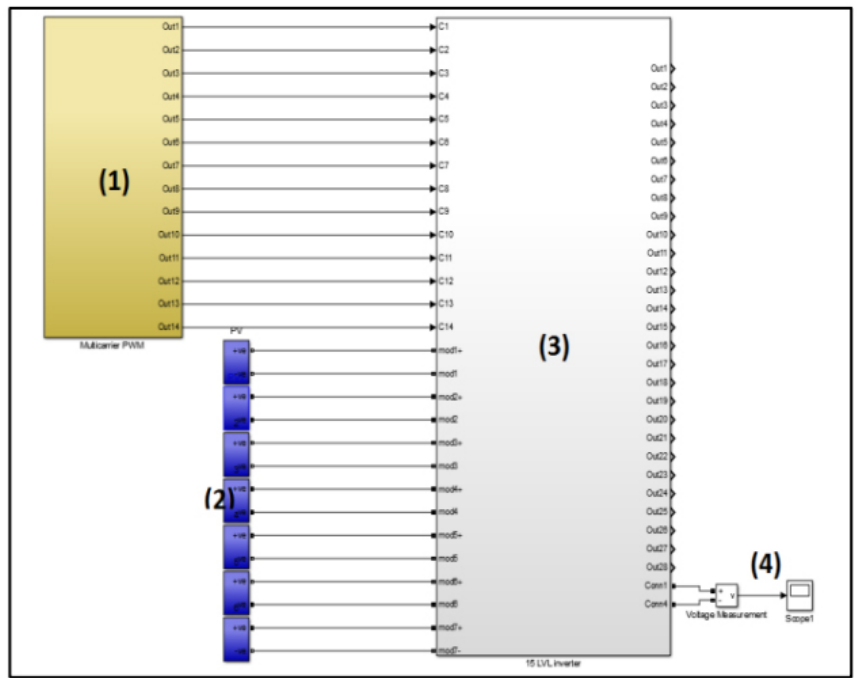

Figure 6 Test setup of Cascaded Fiftheen-Level Inverter 
This setup is devised into four major parts:

Part 1: Multi-carrier PWM techniques are inserted in this part (Command part)

Part 2: Photo-voltaic DC sources or batteries (DC input)

Part 3: Fifteen level inverter components (Multi-inverter)

Part 4: The output voltage after DC conversion (AC output)

\section{Mullti-carrier PWM Analysis Results}

In this paper, the output voltage wave-forms and the total harmonic distortions are acquired from various Multi-carrier SPWM techniques such as;
1. Triangular
2. Trapezoid
3. Modified trapezoid

The results are obtained when using those techniques with different sinusoidal dispositions PD PWM, POD PWM and APOD PWM. The results found are compared with triangular multicarrier to evaluate the harmonics performance.

For comparison, the total harmonic distortions (THD) are evaluated through all the modulation techniques and various frequencies. Higher score of THD means what should claimed.

To acquire the spectrum of the output voltage (THD) Fast Fourier Transform (FFT) is applied. The THD is calculated using the following equation (2):

$$
T H D=\frac{\sqrt{\sum_{n=2}^{\infty} v_{n}^{2}}}{v_{1}}
$$

Where:

$\mathrm{n}$ is the harmonic order.

$\mathrm{v}_{\mathrm{n}}$ is the root mean square (RMS) value of the $\mathrm{nth}$ harmonic component .

$\mathrm{v}_{1}$ is the (RMS) value of the fundamental component.

\subsection{Triangular multi-carrier technique analysis}

This topology uses triangular signals with high frequency as carriers Figure $7 \mathrm{a}$ and constantly compares them to a sinusoidal signal to generate pulses.

For a 15 level inverter, 14 triangular carrier waves Figure $7 \mathrm{~b}$ are required. And all the carrier waves should have similar frequency and the same peak.

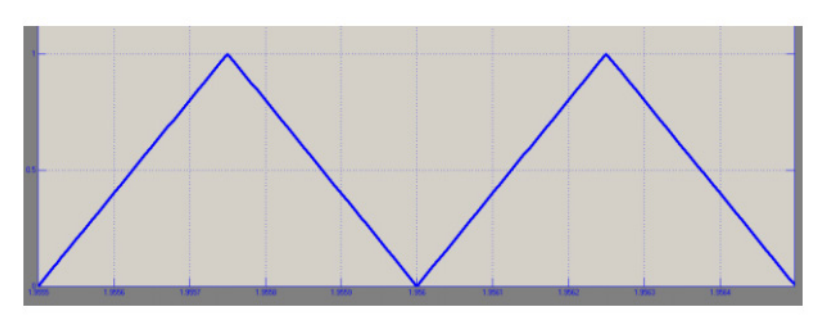

Figure 7a Triangular carrier waveform

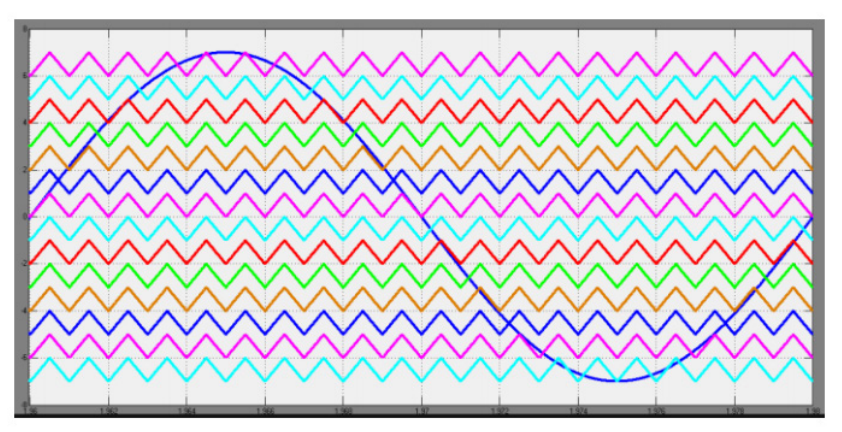

Figure 7b Triangular multi-carrier with $1 \mathrm{Khz}$ frequency

The equation (3) for triangular carrier can be inserted in DSP defined as:

$$
U(t)= \begin{cases}\frac{t}{T / 2} A & 0 \leq t<T / 2 \\ \frac{t}{T-T / 2} A & T / 2 \leq t<T\end{cases}
$$

Where $\mathrm{A}$ is the amplitude and $\mathrm{T}$ is the period of the carrier signal.

As shown in Table 1, THD (the harmonic distortion) are analyzed for different frequencies and with different dispositions. 
Table 1: THD Analyses Using Triangular Carriers

\begin{tabular}{|c|c|c|c|}
\hline Drequencies & PD (\%THD) & POD (\%THD) & APOD (\%THD) \\
\hline $\mathbf{1 ~ K h z}$ & $8.27 \%$ & $8.28 \%$ & $9.45 \%$ \\
\hline $\mathbf{2} \mathbf{~ K h z}$ & $7.87 \%$ & $8.68 \%$ & $8.14 \%$ \\
\hline
\end{tabular}

This table confirms that the best performance for triangular carriers is when phase disposition with $2 \mathrm{KHz}$ frequency is used. Figure 8 shows Fast Fourier analyses of the output signal using triangular carriers with the lowest harmonic results.

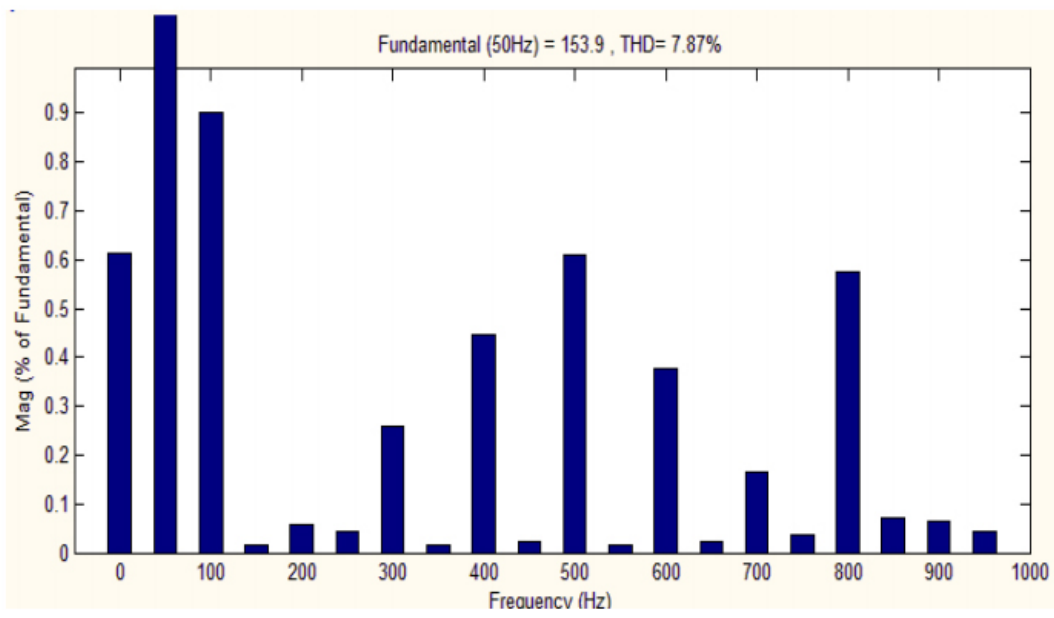

Figure 8 FFT Analysis of Output using Triangular carriers

\subsection{Trapezoidal technique analysis}

Trapezoidal carriers are a combination of two wave forms, triangular in the upper half and trapezoidal in lower part (Figure 9a and $9 \mathrm{~b}$ ). This command technique gives better performance with lower Harmonics [10]. Time between 0-T is equally divided.

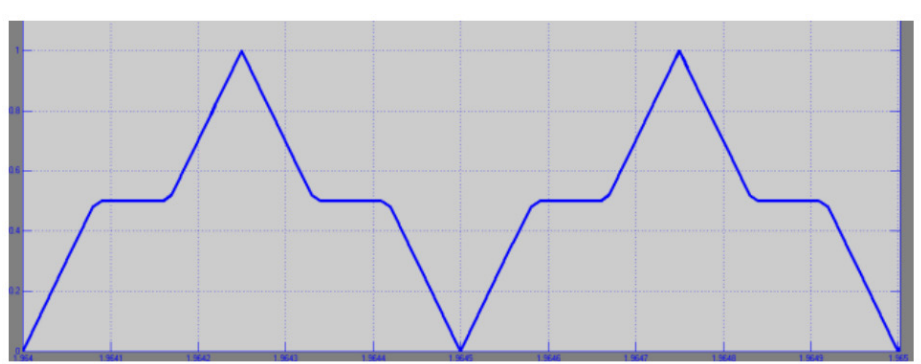

Figure 9a Trapezoidal carrier waveform

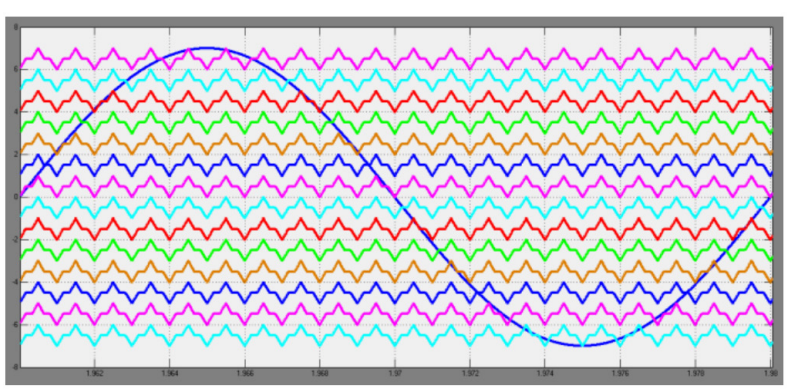

Figure 9b Trapezoidal multi-carrier with $1 \mathrm{Khz}$ frequency

The equation (4) for trapezoidal carriers that can be inserted in DSP defined as:

$$
\mathrm{U}(\mathrm{t})=\left\{\begin{array}{lr}
\frac{6 \mathrm{t}}{\mathrm{T}}\left(\frac{\mathrm{A}}{2}\right) & 0 \leq \mathrm{t}<\mathrm{T} / 6 \\
\mathrm{~A} / 2 & \mathrm{~T} / 6 \leq \mathrm{t}<2 \mathrm{~T} / 6 \\
\frac{\mathrm{t}-\mathrm{T} / 6}{3 \mathrm{~T} / 6-2 \mathrm{~T} / 6}\left(\frac{\mathrm{A}}{2}\right)+\mathrm{A} / 2 & 2 \mathrm{~T} / 6 \leq \mathrm{t}<3 \mathrm{~T} / 6 \\
\frac{4 \mathrm{~T} / 6-\mathrm{t}}{4 \mathrm{~T} / 6-3 \mathrm{~T} / 6}\left(\frac{\mathrm{A}}{2}\right)+\mathrm{A} / 2 & 3 \mathrm{~T} / 6 \leq \mathrm{t}<4 \mathrm{~T} / 6 \\
\mathrm{~A} / 2 & 4 \mathrm{~T} / 6 \leq \mathrm{t}<5 \mathrm{~T} / 6 \\
\frac{\mathrm{T}-\mathrm{t}}{\mathrm{T}-5 \mathrm{~T} / 6}\left(\frac{\mathrm{A}}{2}\right) & 5 \mathrm{~T} / 6 \leq \mathrm{t}<\mathrm{T}
\end{array}\right.
$$


In Table 2, THD are analyzed using trapezoidal carriers, the frequency index and amplitude will be same as triangular carriers.

Table 2: THD Analyses Using Trapezoid Carriers

\begin{tabular}{|c|c|c|c|}
\hline Drequencies & PD (\%THD) & POD (\%THD) & APOD (\%THD) \\
\hline $\mathbf{1 ~ K h z}$ & $7.45 \%$ & $7.88 \%$ & $8.25 \%$ \\
\hline $\mathbf{2} \mathbf{~ K h z}$ & $7.24 \%$ & $7.82 \%$ & $7.44 \%$ \\
\hline
\end{tabular}

This table confirms that the best performance for trapezoidal carriers is when phase disposition with $2 \mathrm{KHz}$ frequency is used and it gives better performance with a gain of $0.63 \%$ lower distortions.

Figure 10 shows Fast Fourier analyses of the output signal using trapezoidal carriers with the lowest harmonic results.

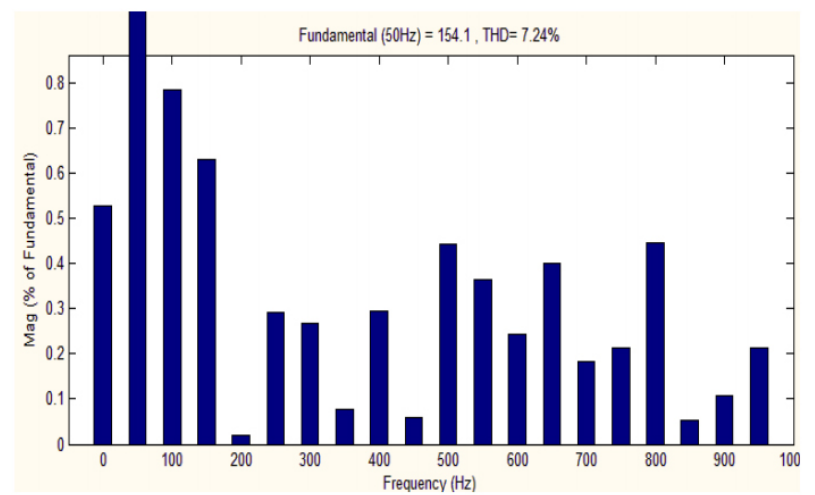

Figure 10 FFT Analysis of Output with lowest harmonics using trapezoidal carriers

\subsection{Modified trapezoid multi-carrier analysis}

The modified technique Figure 11 is based on the trapezoidal and it is made to get better performance of the output signal where the time between 0 -t6 is chosen to get the lowest harmonics possible.

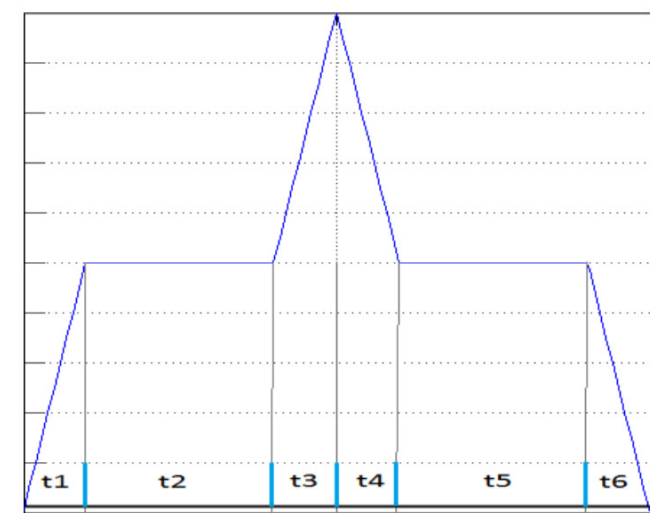

Figure 11a Modified Trapezoidal waveform

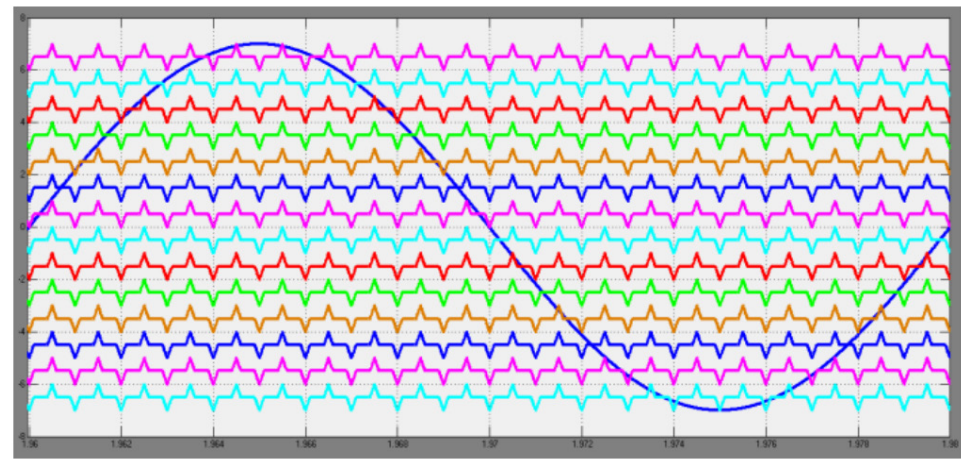

Figure 11b Modified multi-carrier with $1 \mathrm{Khz}$ frequency

The equation (5) for the modified trapezoidal waveform is defined as:

$$
U(t)= \begin{cases}\frac{\mathrm{t}}{\mathrm{t} 1}\left(\frac{\mathrm{A}}{2}\right) & 0 \leq \mathrm{t}<\mathrm{t} 1 \\ \mathrm{~A} / 2 & \mathrm{t} 1 \leq \mathrm{t}<\mathrm{t} 2 \\ {\left[\frac{\mathrm{t}-\mathrm{t} 2}{\mathrm{t} 3-\mathrm{t} 2}\right]\left(\frac{\mathrm{A}}{2}\right)+\mathrm{A} / 2} & \mathrm{t} 2 \leq \mathrm{t}<\mathrm{t} 3 \\ {\left[\frac{\mathrm{t} 4-\mathrm{t}}{\mathrm{t} 4-\mathrm{t} 3}\right]\left(\frac{\mathrm{A}}{2}\right)+\mathrm{A} / 2} & \mathrm{t} 3 \leq \mathrm{t}<\mathrm{t} 4 \\ \mathrm{~A} / 2 & \mathrm{t} 4 \leq \mathrm{t}<\mathrm{t} 5 \\ {\left[\frac{\mathrm{t}-\mathrm{t} 6}{\mathrm{t}-\mathrm{t} 6}\right]\left(\frac{\mathrm{A}}{2}\right)} & \mathrm{t} 5 \leq \mathrm{t}<\mathrm{t} 6\end{cases}
$$


Table 3: THD Analyses Using the proposed technique.

\begin{tabular}{|c|c|c|c|}
\hline Drequencies & DD (\%THD) & POD (\%THD) & APOD (\%THD) \\
\hline $\mathbf{1 ~ K h z}$ & $6.71 \%$ & $7.39 \%$ & $7.20 \%$ \\
\hline $\mathbf{2 ~ K h z}$ & $\mathbf{6 . 5 9 \%}$ & $7.06 \%$ & $6.74 \%$ \\
\hline
\end{tabular}

This table confirms that the best performance for modified trapezoidal carriers is when phase disposition with $2 \mathrm{KHz}$ frequency is used and thus it gives better performance than the previous ones.

Figure 12 shows Fast Fourier analyses of the output signal using modified trapezoidal carriers with the lowest harmonic results.

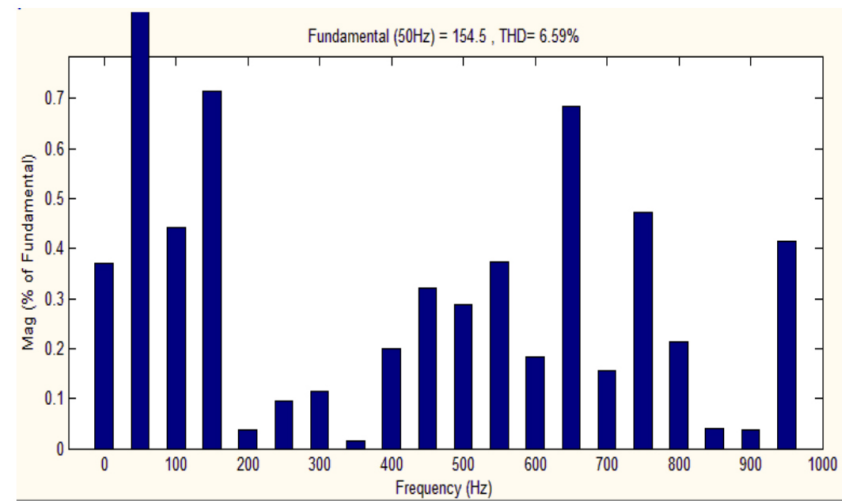

Figure 12 FFT Analysis of Output with lowest harmonics using modified trapezoidal carriers

\section{Results Interpretation}

The table 4 , Figure $13 \mathrm{a}$ and $13 \mathrm{~b}$ resumes all harmonics distortion results for all multi-carrier techniques with different frequencies

Table 4: The Harmonic Distortion Analyses.

\begin{tabular}{|c|c|c|c|c|}
\hline $\begin{array}{c}\text { Techniques } \\
\text { Triangular }\end{array}$ & $1 \mathrm{KHz}$ & $8.27 \%$ & $8.28 \%$ & $\begin{array}{c}\text { Phase } \\
\text { dispositions }\end{array}$ \\
\hline & $2 \mathrm{KHZ}$ & $7.87 \%$ & $8.68 \%$ & $9.45 \%$ \\
\hline Trapezoid & $1 \mathrm{KHz}$ & $7.45 \%$ & $7.88 \%$ & $8.14 \%$ \\
\hline & $2 \mathrm{KHZ}$ & $7.24 \%$ & $7.82 \%$ & $8.25 \%$ \\
\hline Modified & $1 \mathrm{KHz}$ & $6.71 \%$ & $7.39 \%$ & $7.44 \%$ \\
\hline & $2 \mathrm{KHZ}$ & $6.59 \%$ & $7.06 \%$ & $7.20 \%$ \\
\hline
\end{tabular}

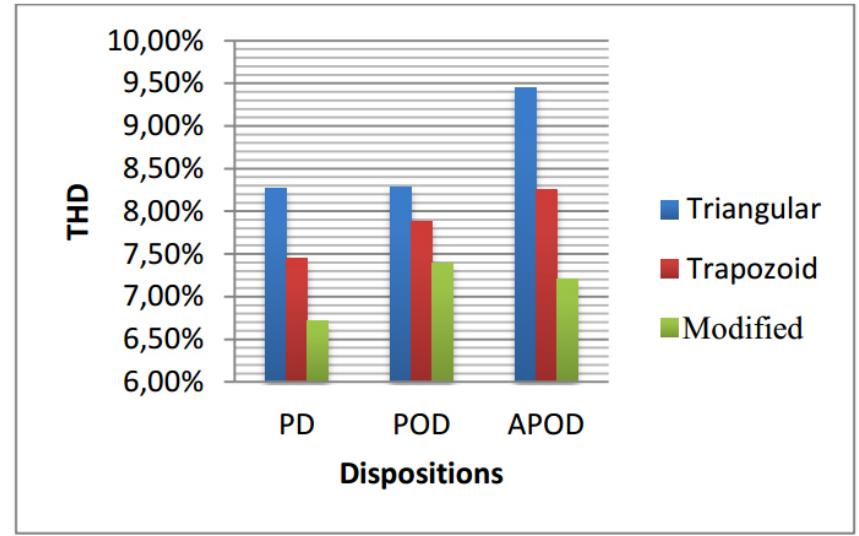

Figure 13a THD analysis for line voltages with $1 \mathrm{KHZ}$ carriers as frequency

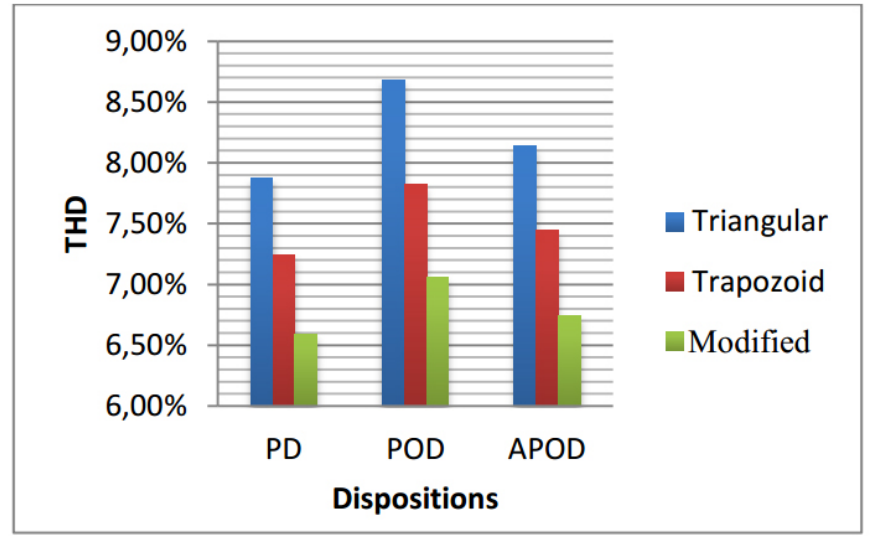

Figure 13b THD analysis for line voltages with $2 \mathrm{KHZ}$ carriers as frequency 
This shows that the best performance is obtained for the proposed technique with better performance it can reach a gain of $1.28 \%$ lower distortions.

\section{Conclusion}

This paper presents simulation results for a Fifteen-Level Inverter using MATLAB SIMULINK. The harmonic distortions can be reduced by the choice of technical PWM control methods. The results illustrate that after modifying the trapezoidal carriers better results are obtained with a gain of $1.28 \%$ compared to the conventional techniques.

So it is clear that this new scheme is best suited for Cascaded Multi-Level with the improvement of the output signal quality which makes it more suitable for both standalone and grid connected systems.

\section{REFERENCES}

[1] Gomez, J., Fernandez, F., Gafaro, F., \& Perelini, F. (2015, October). Application of Grid Studies for the Secure and Optimal Utilisation of Variable Renewables in Islands-Study Case in Samoa. In 5th Solar \& 14th Wind Integration Workshop.

[2] Lee, S. J., Bae, H. S., \& Cho, B. H. (2009, September). Modeling and control of the single-phase photovoltaic gridconnected cascaded H-bridge multilevel inverter. In Energy Conversion Congress and Exposition, 2009. ECCE 2009. IEEE (pp. 43-47). IEEE.

[3] Ahuja, R. K., \& Kumar, A. (2014). MATLAB Simulation and Analysis of Nine-Level Inverter Using Different Schemes of Sinusoidal PWM. International Journal of Innovative Research in Science Engineering and Technology, 6, $13626-13633$.

[4] Alexander, S. (2016). Development of solar photovoltaic inverter with reduced harmonic distortions suitable for Indian sub-continent. Renewable and Sustainable Energy Reviews, 56(C), 694-704.

[5] Vanaja, P., Prasaath, R. A., \& Ganesh, P. (2013). Total harmonic distortion analysis and comparison of diode clamped multilevel Z-source inverter. International Journal of Modern Engineering Research (IJMER), 3(2), 1000-1005.

[6] Mohan, D., \& Kurub, S. B. (2012). A comparative analysis of multi carrier SPWM control strategies using fifteen level cascaded H-bridge multilevel inverter. International Journal of Computer Applications, 41(21).

[7] Umashankar, S., Sreedevi, T. S., Nithya, V. G., \& Vijayakumar, D. (2013). A new 7-level symmetric multilevel inverter with minimum number of switches. ISRN Electronics, 2013.

[8] Suresh, Y., \& Panda, A. K. (2016). Investigation on stacked cascade multilevel inverter by employing single-phase transformers. Engineering Science and Technology, an International Journal, 19(2), 894-903.

[9] Devaraj, S., \& Anitha, G. S. (2015). POD-PWM Based Capacitor Clamped Multilevel Inverter. International Journal of Technical Research and Applications, 3, 80-82.

[10] Paikray, A., \& Mohanty, B. (2014, March). A new multicarrier SPWM technique for five level cascaded H-bridge inverter. In IEEE internationalconf. (ICGCCEE '14) (pp. 1-6). 